\title{
Evaluation of proximate composition, bioactive lignans and volatile composition of Schisandra chinensis fruits from Inje and Mungyeong, Republic of Korea
}

\author{
Kandhasamy Sowndhararajan ${ }^{1}$, Taehee $\mathrm{Kim}^{2}$, Heeyeon $\mathrm{Kim}^{2}$, Songmun Kim ${ }^{1}$ * \\ ${ }^{1}$ Department of Biological Environment, Kangwon National University, Chuncheon 24341, Gangwon-do, Republic of Korea. \\ ${ }^{2}$ Agro-Food Research Institute, Gangwondo Agriculture Research and Extension Services, Chuncheon 24203, Gangwon-do, Republic of Korea.
}

\begin{tabular}{|c|c|}
\hline ARTICLE INFO & ABSTRACT \\
\hline $\begin{array}{l}\text { Article history: } \\
\text { Received on: } 08 / 08 / 2016 \\
\text { Revised on: } 06 / 09 / 2016 \\
\text { Accepted on: } 11 / 10 / 2016 \\
\text { Available online: } 29 / 11 / 2016\end{array}$ & $\begin{array}{l}\text { The present study aimed to determine the proximate composition, mineral content, active ingredients } \\
\text { (schisandrin, schisandrin A, gomisin A and gomisin N) and volatile composition of Schinsandra chinensis fruits } \\
\text { collected from Inje and Mungyeong, two major cultivating areas in Republic of Korea. The bioactive ingredients } \\
\text { were determined by high performance liquid chromatography (HPLC). The volatile composition of the } \\
\text { supercritical carbon dioxide extracts (SFE) from the fruits of S. chinensis was determined by solid phase }\end{array}$ \\
\hline $\begin{array}{l}\text { Key words: } \\
\text { Omija, Schisandra chinensis, } \\
\text { Schisandrin, Supercritical } \\
\text { fluid extract, Volatile. }\end{array}$ & $\begin{array}{l}\text { found to be higher in Mungyeong than Inje samples. The minerals such as Mn, Ca and P were higher in the } \\
\text { samples obtained from Inje when compared with Mungyeong. The active ingredients such as schisandrin } \\
(5018.67 \mu \mathrm{g} / \mathrm{g} \text { ), gomisin N ( } 4772.87 \mu \mathrm{g} / \mathrm{g} \text { ) and schisandrin A }(717.18 \mu \mathrm{g} / \mathrm{g} \text { ) were found to be higher level in } \\
\text { Mungyeong samples with the exception of gomisin A. The SPME-GC/MS analysis revealed the identification } \\
\text { of } 40 \text { components from each place, representing } 97.22 \% \text { (Inje) and } 96.81 \% \text { (Mungyeong) of the SFE. Ylangane, } \\
\alpha \text {-himachalene, longipinene and italicene were detected as the major components in the SFE. In conclusion, Inje } \\
\text { and Mungyeong are the suitable places to collect } S \text {. chinensis fruits with higher level of nutrient and chemical } \\
\text { contents. }\end{array}$ \\
\hline
\end{tabular}

\section{INTRODUCTION}

The genus Schisandra belongs to the family of Schisandraceae and contains 23 deciduous vine species that are widely distributed in East Asia. In the genus, Schisandra chinensis (Turcz.) Baill. is an important traditional medicinal plant and mainly cultivated in northeastern regions of China, Japan, Korea and Russia (Sun et al., 2010). This cash crop has been cultivated in alpine areas of Republic of Korea and the quality has been known to be determined by the climate of cultivating areas. The fruits of S. chinensis (Korean name omija) are traditionally used for the treatment of various

\footnotetext{
* Corresponding Author

Songmun Kim, Department of Biological Environment, Kangwon National University, Chuncheon 24341, Gangwon-do, Republic of Korea Email:perfume@kangwon.ac.kr
}

disorders such as cough, spontaneous sweating, palpitation, spermatorrhea, dyspnea, kidney disorders, mouth dryness, dysentery and amnesia (Wang et al., 2008; Teng and Lee, 2014). The fruits contain various bioactive components including essential oil, organic acids, vitamins, lignans, terpenes, amino acids, polysaccharides, etc (Huang et al., 2008; Stacchiotti et al., 2009; Gao et al., 2009; Lu and Chen, 2009). Among them, lignans and the essential oil with terpenes are the most bioactive ingredients in the fruits of S. chinensis (Wang et al., 2008). Pharmacological studies have showed that the lignans exhibited various biological activities, including hepatoprotective, anticancer, antioxidant, cardioprotective, adaptogenic and central nervous system protecting activities etc. (Jiang et al., 2005; Huang et al., 2007; Hu et al., 2012; 2013). Owing to the wide range of bioactive properties, the consumption of $S$. chinensis fruits has gained increasing popularity as dietary supplements. 
In addition to lignans, the volatile components from the fruit of $S$. chinensis were widely used in pharmaceuticals and cosmetic industries. The steam distillation or hydrodistillation is a conventional method widely used to isolate the volatile components from various medicinal and aromatic plant materials (Herrero et al., 2010).

However, the conventional techniques have many disadvantages such as low extraction efficiency, longer extraction time and toxic solvent residue. Further, the essential oil quality is also highly affected due to the effect of the high temperatures (Fornari et al., 2012).

Previously, some authors have reported the volatile composition of $S$. chinensis fruits obtained from steam distillation, supercritical fluid extraction (SFE), Soxhlet, microwave assisted extraction and headspace solid-phase micro-extraction (SPME) methods (Deng et al., 2003; Li et al., 2003; Wang et al., 2008; Chen et al., 2012; Teng and Lee, 2014). In recent times, SFE has attracted significant attention as an effective and environmentally friendly extraction technique to replace conventional methods (Capuzzo et al., 2013). The SFE method has been developed significantly in the extraction of $S$. chinensis fruits, but most of the studies are related to the extraction of lignans (Wang et al., 2008). Furthermore, SPME combined with GC/MS is a novel technique, solvent-free, rapid and very simple to extract and detect the volatile components (Delgado et al., 2010). Hence, SPME-GC/MS was used in the present study to analyze the volatile composition of SFE from the fruits of $S$. chinensis .

According to the previous results, there were considerable qualitative and quantitative variations in the volatile composition from the fruits of $S$. chinensis and these variations might be influenced by various biotic and abiotic factors (Dhouioui et al., 2016). In the previous studies, the samples were mainly collected from China in relation to volatile composition of S. chinensis .

In addition, Inje and Mungyeong are the two major cultivating areas of $S$. chinensis in Republic of Korea, but there has been no comparative study on the nutritional and chemical composition of this fruit. Further, there is no report on volatile composition of SFE of $S$. chinensis fruits using SPME-GC/MS. Therefore, the present study was designed with the aim of determining and comparing the proximate composition, mineral content, active ingredients and volatile composition of S.chinensis fruits collected from Inje (Gangwon-do) and Mungyeong (Gyeongsangbuk-do) in Republic of Korea.

\section{MATERIALS AND METHODS}

\section{Materials}

The matured and dried fruits of $S$. chinensis were procured from different locations of Inje (10 places) and Mungyeong (10 places) in Republic of Korea during February 2014 (Fig. 1). The lignans such as schisandrin, schisandrin A, gomisin $\mathrm{A}$ and gomisin $\mathrm{N}$ were purchased from Sigma-Aldrich
Chemicals (St. Louis, MO, USA). All other chemicals and solvents used in the study were of analytical grade.

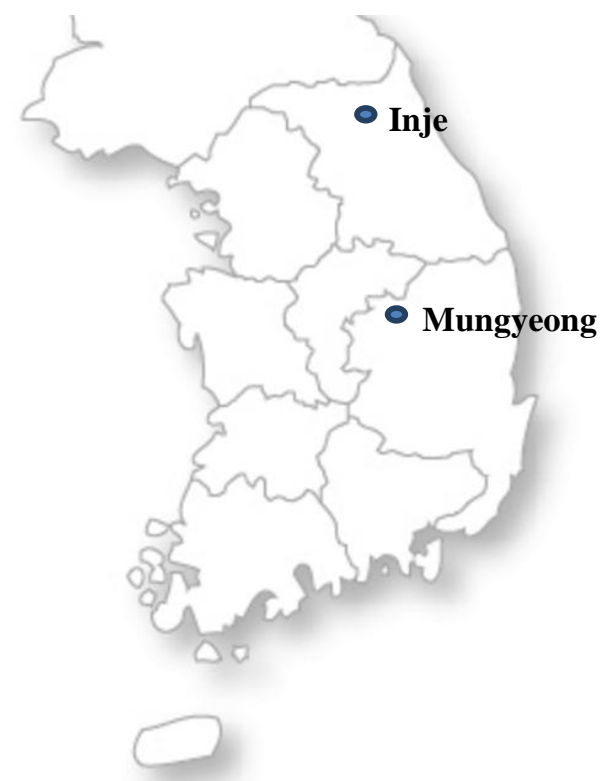

Fig. 1: Map of Inje and Mungyeong, the two major cultivating areas of Schinsandra chinensis fruits in Republic of Korea.

\section{Analysis of proximate composition}

In the proximate composition, moisture, crude protein, crude lipid, crude fiber and ash contents of $S$. chinensis fruit samples were determined by standard methods (AOAC, 2000). Moisture content of sample was determined using the direct drying method. The sample was dried in a hot air-oven set at $105^{\circ} \mathrm{C}$ until constant weight of the sample was obtained. Protein content of the sample was determined according to the principle of Kjeldahl method. A conversion factor of 6.25 was used to convert the measured nitrogen content to protein content. Lipid content of sample was determined by using a Soxhlet extractor with diethyl ether as solvent. The crude fiber was determined by alternately digesting the dried, defatted sample in $1.25 \% \mathrm{HCl}$ and $1.25 \%$ $\mathrm{NaOH}$. Ash content of sample was determined using the dry ashing method. The sample was incinerated in a cold muffle furnace set at $550^{\circ} \mathrm{C}$ until whitish/greyish ash was obtained.

\section{Determination of mineral composition}

The minerals such as iron (Fe), manganese $(\mathrm{Mn})$, copper $(\mathrm{Cu})$, calcium $(\mathrm{Ca})$, potassium $(\mathrm{K})$, magnesium $(\mathrm{Mg})$, sodium $(\mathrm{Na})$, and phosphorus $(\mathrm{P})$ were determined in the fruit samples from Inje and Mungyeong. Ten milliliters of concentrated $\mathrm{HNO}_{3}$ (70\%) were added to $0.2 \mathrm{~g}$ of the fruit samples in a test tube. The dispersion was digested in a digestion block at $100^{\circ} \mathrm{C}$ for $3 \mathrm{~h}$. After cooling, the digested products were diluted to $40 \mathrm{ml}$ with deionized water, and centrifuged at $5000 \mathrm{rpm}$ for $10 \mathrm{~min}$. The clear solution was used for mineral determination by an inductively coupled plasma-optical emission spectrometer(Integra XL, GBC Scientific, Australia). For P, absorbance was measured in a UV-visible spectrophotometer (HP 8453E, Hewlett-Packard 
Co., USA) at $420 \mathrm{~nm}$. The results are expressed as $\mathrm{g} / 100 \mathrm{~g}$ dry weight of sample for each mineral element.

\section{Quantitative determination of active components by HPLC}

The dried and pulverized fruits of $S$. chinensis $(0.3 \mathrm{~g})$ were extracted with $25 \mathrm{ml}$ of methanol in an ultrasonic bath for 30 $\mathrm{min}$ at room temperature and centrifuged for $10 \mathrm{~min}$ at 5,000 rpm. Then the supernatant was filtered through $0.45 \mu \mathrm{m}$ membrane syringe filter and the filtrate was used for HPLC analysis.

The active components (lignans) were quantified by Shiseido NANOSPACE SI-2 HPLC system (Shiseido, Tokyo, Japan). The standard stock solutions of schisandrin, schisandrin A, gomisin $\mathrm{A}$ and gomisin $\mathrm{N}$ were prepared in methanol. Chromatographic separation was performed using a reversedphase column Unison UK-C18 (4.6 $\mathrm{mm} \times 150 \mathrm{~mm} \times 3 \mu \mathrm{m})$ at a column temperature of $30^{\circ} \mathrm{C}$. The mobile phases used to elute were distilled water (A) and acetonitrile (B), with an isocratic condition (A, $40 \%$ and $\mathrm{B}, 60 \%$ ) for $30 \mathrm{~min}$. The injection volume of the sample was set at $10 \mu \mathrm{L}$, with a fixed flow rate of $1 \mathrm{~mL} / \mathrm{min}$, and the detector wavelength was set to $254 \mathrm{~nm}$ (Accela PDA, Thermo Fischer Scientific, Bremen, Germany).

\section{Supercritical $\mathrm{CO}_{2}$ extraction (SFE)}

The SFE was performed by ISA-SCCO-S-050-500 (ILSHIN Autoclave Co. Ltd., Daejeon, Republic of Korea). A hundred grams of dried fruits (not-pulverized) were loaded into a stainless steel extraction vessel. And the $\mathrm{CO}_{2}$ was pressurized with a high-pressure pump and then charged into the extraction column to desired pressure. Back pressure regulators are used to set the system pressure (in extractor and separator). To optimize the SFE conditions for $S$. chinensis fruits, the extraction was conducted at different pressures (200, 300 and 400 bar) and temperatures (40, 50,60 and $70^{\circ} \mathrm{C}$ ). The $\mathrm{CO}_{2}$ flow rate was maintained at 30 $\mathrm{mL} / \mathrm{min}$. Each extraction process was performed for $60 \mathrm{~min}$ and the yield of extract obtained from the different extraction conditions was expressed as percent of the dry weight of fruits.

\section{Solid phase microextraction (SPME) conditions}

SFE (1 g) obtained from the fruits of $S$. chinensis was introduced into SPME vial $(20 \mathrm{~mL})$. The SPME device coated (fused-silica fiber) with a $100 \mu \mathrm{m}$ layer of polydimethylsiloxane (Supelco, Bellefonte, PA, USA) was used for extraction of the volatiles and the vial was sealed with a silicone septum. The fiber was exposed in the SPME vial at $60^{\circ} \mathrm{C}$ for $30 \mathrm{~min}$ and immediately introduced in the gas chromatography injector.

\section{Gas chromatography/mass spectrometry (GC/MS) analysis}

GC-MS analysis was performed with a Varian CP 3800 gas chromatography equipped with a VF-5 MS polydimethylsiloxane capillary column $(30 \times 0.25 \mathrm{~mm} \times 0.25 \mu \mathrm{m})$ and a Varian $1200 \mathrm{~L}$ mass detector (Varian, CA, USA). Helium was used as a carrier gas at the rate of $1 \mathrm{~mL} / \mathrm{min}$. Oven temperature was kept at $50^{\circ} \mathrm{C}$ for $5 \mathrm{~min}$ initially, and then raised with rate of $5^{\circ} \mathrm{C} / \mathrm{min}$ to $250^{\circ} \mathrm{C} / \mathrm{min}$. The injected volume of essential oil was $10 \mu \mathrm{L}$ with a split ratio of $1: 10$. The injector temperature was set at $250^{\circ} \mathrm{C}$. The mass spectra were recorded in the electrospray ionization mode at $70 \mathrm{eV}$ in a scan range of 50 $600 \mathrm{~m} / \mathrm{z}$. The components of essential oils were identified by comparing the retention indices of the GC peaks obtained using homologous series of $n$-alkanes $\left(\mathrm{C}_{8}-\mathrm{C}_{20}\right)$ with those reported in literature (Adams, 2007). The mass spectra of the peaks were also matched with standards reported in literature and National Institute of Standards and Technology (NIST, 3.0) library.

\section{RESULTS AND DISCUSSION}

\section{Proximate composition and mineral content of Schisandra chinensis fruits}

In the proximate composition analysis, moisture, crude protein, lipid and fiber and ash contents of the fruit samples obtained from Inje and Mungyeong were determined. The mean value of proximate composition for the fruits of $S$. chinensis is shown in Table 1. The moisture value of the fruits from Inje and Mungyeong were $3.88 \%$ and $3.81 \%$, respectively. The major proximate components in the fruit samples of Inje and Mungyeong were crude lipid (13.51\% and $14.73 \%$, respectively) and crude fiber ( $13.77 \%$ and $14.19 \%$, respectively) followed by crude protein $(9.50 \%$ and $10.58 \%$, respectively). The fruit samples also registered considerable amount of ash content (Inje - 5.41\% and Mungyeong - $6.11 \%$ ). From the results, the fruit samples from Mungyeong possess higher level of proximate composition than Inje samples.

Table 1: Proximate composition and mineral content of fruits of Schisandra chinensis from two different places (Inje and Mungyeong).

\begin{tabular}{ccc}
\hline Content & Inje & Munkyong \\
\hline Proximate composition (\%) & & \\
\hline Moisture & $3.88 \pm 0.79^{*}$ & $3.81 \pm 0.87$ \\
Crude protein & $9.50 \pm 1.81$ & $10.58 \pm 0.78$ \\
Crude lipid & $13.51 \pm 1.38$ & $14.73 \pm 1.46$ \\
Ash & $5.41 \pm 1.76$ & $6.11 \pm 0.67$ \\
Crude fiber & $13.77 \pm 1.51$ & $14.19 \pm 1.23$ \\
\hline Mineral content (mg/100 g) & & \\
\hline Iron (Fe) & $13.43 \pm 3.15$ & $15.03 \pm 3.93$ \\
Manganese (Mn) & $6.49 \pm 4.04$ & $5.61 \pm 3.26$ \\
Copper (Cu) & $0.48 \pm 0.10$ & $0.48 \pm 0.11$ \\
Calcium (Ca) & $82.92 \pm 17.95$ & $78.46 \pm 9.96$ \\
Potassium (K) & $1085.82 \pm 390.57$ & $1246.53 \pm 312.40$ \\
Magnesium (Mg) & $124.71 \pm 26.09$ & $129.05 \pm 27.94$ \\
Sodium (Na) & $14.37 \pm 1.26$ & $14.71 \pm 1.95$ \\
Phosphorus (P) & $0.07 \pm 0.09$ & $0.05 \pm 0.01$ \\
\hline
\end{tabular}

*Values are mean of three replicate determinations $(\mathrm{n}=10) \pm$ standard deviation.

In general, a significant amount of ash content specified the presence of appreciable amounts of inorganic nutrients in the plant materials. The presence of substantial amount of lipids reveals the potential of this fruits to have dietary purposes with good nutritional qualities (Iqbal et al., 2012). Further, the fruits also possess considerable amount of crude fiber and crude protein contents. The results of proximate composition indicated the fruits of $S$. chinensis possess a high nutritional value. Previously, Kim 
and Choi (2008) investigated the physicochemical and antioxidative properties of $S$. chinensis fruits. The fruits contained $57.5 \%$ of moisture, $18.8 \%$ of crude fat, $12.6 \%$ of carbohydrate, $11.1 \%$ of crude protein, $4.9 \%$ of ash and $5.4 \%$ of crude fiber. The authors also reported the amino acid contents of the fruits with the largest portion of glutamic acid $131.7 \mathrm{mg} / 100 \mathrm{~g}$ followed by $51.5 \%$ aspartic acid. In addition, the fruits contained 7 types of free sugar contents with the glucose and fructose were registered as the dominant sugars.

It is essential to understand the chemical composition of the fruits, especially the composition of minerals and other trace elements, because the mineral composition of foods has a fundamental role in the diet of human. Table 1 shows the mineral contents of $S$. chinensis fruit samples from Inje and Mungyeong. The mineral composition of $S$. chinensis fruit samples varied considerably between two different places. Among the macrominerals, $\mathrm{K}$ was the most concentrated mineral in the fruits from both the places, Inje and Mungyeong (1085.82 and 1246.53 $\mathrm{mg} / 100 \mathrm{~g}$, respectively) followed by $\mathrm{Mg}$ (124.71 and 129.05 $\mathrm{mg} / 100 \mathrm{~g}$, respectively) and $\mathrm{Ca}(82.92$ and $78.46 \mathrm{mg} / 100 \mathrm{~g}$, respectively). Fe was the most concentrated micro-mineral in the fruits of Inje and Mungyeong (13.43 and $15.03 \mathrm{mg} / 100 \mathrm{~g}$, respectively) followed by $\mathrm{Mn}$ (6.49 and $5.61 \mathrm{mg} / 100 \mathrm{~g}$, respectively). Among the eight minerals analyzed, $\mathrm{Fe}, \mathrm{Cu}, \mathrm{Mg}$ and $\mathrm{Na}$ contents were found to be higher in the Mungyeong samples than Inje samples. These minerals are essential for the correct functioning of the human body.

The composition of minerals and other nutrients in the plant materialis mainly influenced by various biotic and abiotic factors. Hwang et al. (2015) studied the mineral contents of $S$. chinensis fruits from Korea and China. The mineral contents of $S$. chinensis fruits from China $(100 \mathrm{~g})$ were $\mathrm{K}(923.31 \mathrm{mg}), \mathrm{Mg}$ (83.91 mg), Ca (14.80 mg), Mn (6.19 mg), Fe (4.30 mg), Zn (1.12 $\mathrm{mg}), \mathrm{Na}(2.20 \mathrm{mg})$ and $\mathrm{Cu}(0.30 \mathrm{mg})$. In addition, the authors reported that the contents of $\mathrm{K}$ and $\mathrm{Zn}$ were found to be significantly higher in Korean fruits than the Chinese fruits. Kim and Choi (2008) reported the presence of 10 minerals in the fruits with the highest levels of $\mathrm{K}(912.6 \mathrm{mg} / 100 \mathrm{~g})$ and $\mathrm{Ca}(613.8$ $\mathrm{mg} / 100 \mathrm{~g}$ ), followed by $\mathrm{Al}, \mathrm{Mg}, \mathrm{Na}$ and $\mathrm{Mn}$. The present study also confirmed that the fruit samples comprised higher levels of $\mathrm{K}$, $\mathrm{Mg}$ and $\mathrm{Ca}$ minerals. Further, these nutrients were found to be higher in the current study when compared to that of previous reports. Potassium is an essential nutrient and has an important role in the synthesis of amino acids and proteins. Nour et al. (2014) stated that the nutrition with a high ratio of $\mathrm{K} / \mathrm{Na}$ have been associated with a lower incidence of hypertension.

\section{Active components}

Previously, a number of studies have reported that the lignans from $S$. chinensis possess various pharmacological properties, such as hepatoprotective, antioxidant and anticarcinogenic activities, and strong inhibitory effect on human immunodeficiency virus (Wang et al., 2008; Choi et al., 2006; Ip et al., 1996; Lee and Kim et al., 2010; Xie et al., 2010). Further, those studies suggest that the bioactive lignans mainly comprised of dibenzocyclooctadiene skeletons with (S)- or (R)-biphenyl configurations. Until now, more than 40 lignans have been characterized from the different organs of S. chinensis (Kim et al., 2010; Takimoto et al., 2013).

In the present study, the most bioactive lignans such as schisandrin, schisandrin $\mathrm{A}$, gomisin $\mathrm{A}$ and gomisin $\mathrm{N}$ were quantified by HPLC (Fig. 2). The fruits contained the highest amount of schisandrin followed by gomisin $\mathrm{N}$, gomisin $\mathrm{A}$ and schisandrin A. When compared to the fruit samples of Inje, the contents of schisandrin $(5018.67 \mu \mathrm{g} / \mathrm{g})$, gomisin $\mathrm{N}(4772.87 \mu \mathrm{g} / \mathrm{g})$ and schisandrin A $(717.18 \mu \mathrm{g} / \mathrm{g})$ were higher in the samples of Mungyeong. The level of Gomisin A was higher in Inje samples $(1383.03 \mu \mathrm{g} / \mathrm{g})$ than Mungyeong samples $(1202.60 \mu \mathrm{g} / \mathrm{g})$.

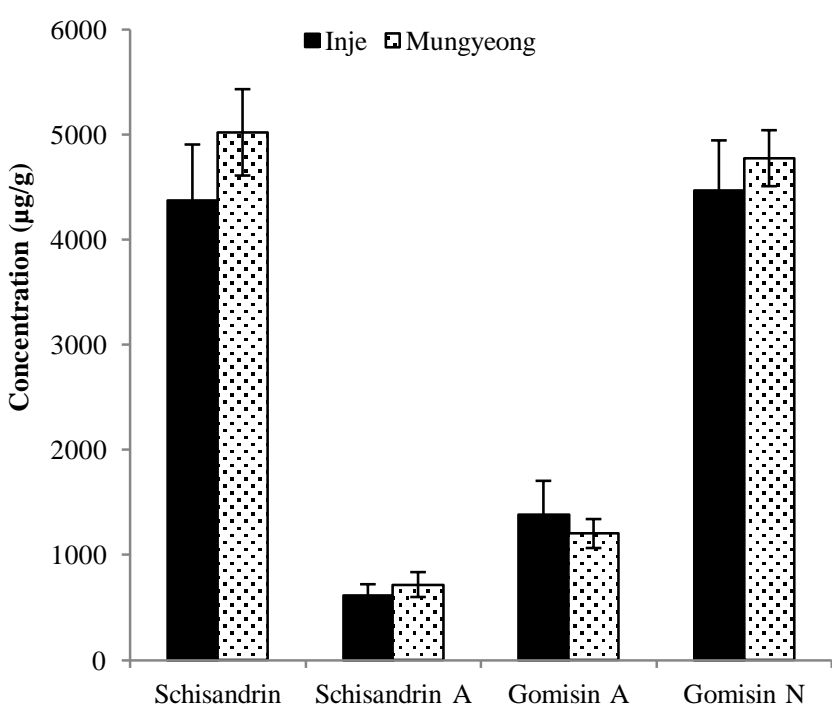

Fig. 2: Active ingredients in the fruits of Schisandra chinensis from two different places (Inje and Mungyeong). Values are mean of three replicate determinations $(n=10) \pm$ standard deviation.

Zhang et al. (2009) established a rapid and specific HPLC method for simultaneous determination of six major lignans in S.chinensis such as schisandrin, schisandrol B, schisantherin A, deoxyschisandrin, $\gamma$-schisandrin and schisandrin $\mathrm{C}$. The six lignans were successfully separated on a $\mathrm{C} 18$ column and the mobile phase consisted of acetonitrile and water with the detection wavelength of $225 \mathrm{~nm}$. In addition, Hu et al. (2013) successfully validated the method to quantify 11 lignans (schisandrin, gomisin $\mathrm{J}$, schisandrol B, angeloylgomisin $\mathrm{H}$, gomisin $\mathrm{G}$, schisantherin A, schisantherin B, deoxyschisandrin, $\gamma$-schisandrin, schisandrin B and schisandrin C) in S. chinensis by HPLC. Recently, a simplified sample extraction method using matrix solid phase dispersion followed by HPLC determination was established for the determination of five most abundant lignans, schisandrin, schisandrol B, schisantherin A, deoxyschisandrin and $\gamma$ schisandrin in S. chinensis (Zhang et al., 2016). In the current study, schisandrin was the most abundant component in the fruits followed by gomisin $\mathrm{N}$, gomisin $\mathrm{A}$ and schisandrin $\mathrm{A}$. The contents of schisandrin, gomisin $\mathrm{N}$ and schisandrin $\mathrm{A}$ were found 
to be higher in Mungyeong samples than Inje samples. However, the concentration and distribution of these lignans in S. chinensis are mainly influenced by plant origins and harvest seasons. Among the various lignans, schisandrin is a prominent lignin with multiple pharmacological properties including antioxidant, antiinflammatory, antitumor, sedative and hepatoprotective effects (Park et al., 2011; Kang et al., 2012; Zhang et al., 2016). Previous studies have shown that the lignans, gomisin $\mathrm{N}$ and gomisin $\mathrm{A}$, significantly inhibited the liver damage from toxic chemicals. Gomisin A has been shown to inhibit acetylcholinesterase activity and anti-hypertensive effect and improve scopolamine-induced memory impairment in mice. Gomisin A showed antiinflammatory properties by potentially inhibiting the proinflammatory mediators through the down-regulation of receptorinteracting protein 2 and activation of nuclear factor-kappa B (Park et al., 2012; Jeong et al., 2014). Schisandrin B (gomisin N) enhanced the cytotoxic and pro-apoptotic potentials of doxorubicin (Li et al., 2006; Kim et al., 2010). Gomisin N remarkably inhibited the nitric oxide production in lipopolysaccharide-induced RAW 264.7 cells and reduced the mRNA expression and the secretion of pro-inflammatory mediators (Oh et al., 2010). In addition, gomisin $\mathrm{N}$ exhibited antiproliferative properties against various cancer cell lines with the $\mathrm{IC}_{50}$ values of $10-70 \mu \mathrm{M}$ (Min et al., 2008). Furthermore, Giridharan et al. $(2011$; 2012) reported that the lignan, schisandrin B effectively prevent scopolamine-induced dementia and cisplatin-induced memory deficits in animal model. Schisandrin A is also an important bioactive lignan and is a strong antioxidant which possesses hepatoprotective and antitumor properties. It also showed positive effects on preventing memory impairment in mice (Hu et al., 2012; Cheng et al., 2013; Lu et al., 2014).

\section{Volatile composition of SFE}

The SFE yield of $S$. chinensis fruits was significantly influenced by the extraction temperature and pressure. In the different pressures performed for the optimization of extraction condition, there were no yield at 200 and 300 bar. Further, the yield was increased with increase of temperature $\left[50^{\circ} \mathrm{C}(0.01 \%)\right.$, $60{ }^{\circ} \mathrm{C}(0.02 \%)$ and $\left.70^{\circ} \mathrm{C}(0.45 \%)\right]$ at constant pressure of 400 bar. At the constant temperature $\left(70{ }^{\circ} \mathrm{C}\right.$ ) and pressure $(400$ bar), the SFE yields of Inje and Mungyoeng samples were $0.42 \pm 0.13 \%$ and $0.45 \pm 0.13 \%$, respectively. The results revealed that the pressure plays a vital role in the extraction yield of $S$. chinensis fruits when compared with the temperature. Previously, several studies have reported that the temperature and pressure played an important role on the yield of essential oils from various plant materials by SFE method (Ansari and Goodarznia, 2012; Ahmed et al., 2012). Wang et al. (2008) obtained the SFE yield of $185.6 \mathrm{mg} / \mathrm{g}$ from the fruits of $S$. chinensis with the operating conditions of pressure, 25 $\mathrm{MPa}$; temperature, $50^{\circ} \mathrm{C}$; carbon dioxide flow rate, $25 \mathrm{~L} / \mathrm{h}$; and extraction time, $3 \mathrm{~h}$. In the present study, the SFE yield was very low, because the fruits samples were not pulverized as well as the extraction time was 1 hour. The volatile composition of the SFE from $S$. chinensis fruits was determined by SPME-GC/MS and the result is presented in Table 2 .

Table 2: Volatile composition of supercritical carbon dioxide extract of Schisandra chinensis fruits from two different places (Inje and Mungyeong)

\begin{tabular}{|c|c|c|c|c|}
\hline \multirow[t]{2}{*}{ No. ${ }^{a}$} & \multirow[t]{2}{*}{ Components $^{\mathrm{b}}$} & \multirow[t]{2}{*}{$\mathbf{R I}^{\mathbf{c}}$} & \multicolumn{2}{|c|}{ Area (\%) } \\
\hline & & & Inje & $\begin{array}{l}\text { Mung } \\
\text { yeong }\end{array}$ \\
\hline \multicolumn{5}{|c|}{ Monoterpene hydrocarbons } \\
\hline 1 & $\alpha$-Pinene & 939 & 0.27 & 0.27 \\
\hline 2 & Camphene & 954 & 0.43 & 0.29 \\
\hline 3 & Sabinene & 975 & 0.15 & 0.17 \\
\hline 4 & $\beta$-Pinene & 979 & 0.17 & 0.19 \\
\hline 5 & $\beta$-Myrcene & 990 & 0.36 & 0.26 \\
\hline 6 & 2-Carene & 1002 & 0.45 & 0.45 \\
\hline 7 & o-Cymene & 1026 & 0.36 & 0.25 \\
\hline 8 & Limonene & 1029 & 0.41 & 0.31 \\
\hline 9 & $\gamma$-Terpinene & 1059 & 1.34 & 1.43 \\
\hline 10 & Terpinolene & 1088 & 0.18 & - \\
\hline \multicolumn{5}{|c|}{ Oxygenated monoterpenes } \\
\hline 11 & Citronellal & 1153 & 0.09 & 0.10 \\
\hline 12 & Borneol & 1169 & 0.34 & 0.14 \\
\hline 13 & Terpinen-4-ol & 1177 & 0.25 & 0.18 \\
\hline 14 & Sabinene hydrate acetate & 1221 & 0.66 & 0.21 \\
\hline 15 & Thymol methyl ether & 1235 & 1.45 & 1.82 \\
\hline 16 & Bornyl acetate & 1285 & 3.54 & 4.31 \\
\hline 17 & Myrtanyl acetate & 1326 & 2.80 & 1.80 \\
\hline 18 & 1,4-Dimethoxy-2-tert-butylbenzene & 1365 & 1.38 & 1.55 \\
\hline \multicolumn{5}{|c|}{ Sesquiterpene hydrocarbons } \\
\hline 19 & Cyclosativene & 1371 & 0.54 & 0.30 \\
\hline 20 & Ylangene & 1375 & 17.66 & 25.66 \\
\hline 21 & $\beta$-Cubebene & 1388 & 1.69 & 2.90 \\
\hline 22 & $\beta$-Elemene & 1390 & 1.44 & 1.93 \\
\hline 23 & Longipinene & 1400 & 10.09 & 8.69 \\
\hline 24 & Italicene & 1405 & 5.32 & 4.86 \\
\hline 25 & Caryophyllene & 1419 & 2.97 & 2.66 \\
\hline 26 & Seychellene & 1446 & 1.65 & 2.45 \\
\hline 27 & $\alpha$-Himachalene & 1451 & 20.70 & 18.03 \\
\hline 28 & $\beta$-Farnesene & 1456 & 1.54 & 0.96 \\
\hline 29 & Acoradiene & 1466 & - & 2.57 \\
\hline 30 & $\gamma$-Muurolene & 1479 & 1.71 & 1.78 \\
\hline 31 & $\alpha$-Calacorene & 1545 & 0.40 & 0.15 \\
\hline \multicolumn{5}{|c|}{ Oxygenated sesquiterpenes } \\
\hline 32 & Germacrene B & 1561 & 0.60 & 0.90 \\
\hline 33 & Humulane-1,6-dien-3-ol & 1611 & 1.68 & 0.24 \\
\hline 34 & Aromadendrene epoxide & 1641 & 3.72 & 2.74 \\
\hline 35 & Cedr-8-en-15-ol & 1644 & 3.88 & - \\
\hline 36 & Cubenol & 1646 & 1.45 & 2.01 \\
\hline 37 & $\alpha$-Cadinol & 1654 & 0.78 & 0.29 \\
\hline 38 & Bisabolol & 1685 & 1.94 & 1.43 \\
\hline 39 & Longipinocarvone & 1775 & 1.21 & 0.58 \\
\hline 40 & Nootkatone & 1806 & - & 0.22 \\
\hline 41 & (E,E)-Farnesyl acetate & 1822 & 1.20 & 1.51 \\
\hline \multirow[t]{2}{*}{42} & Methyl hinokiate & 1865 & 0.42 & 0.22 \\
\hline & & & 97.22 & 96.81 \\
\hline
\end{tabular}

${ }^{a}$ In order of elution on VF-5ms. ${ }^{b}$ Components identified based on mass spectra and retention indices. ${ }^{c} \mathrm{RI}$, Retention indices reported in the literature. The SFE of fruits obtained from 10 sites of each place were pooled together and used for the SPME-GC/MS analysis.

A total of 42 components were identified in the SFE of fruits obtained from Inje and Mungyeong, accounting for 97.22 and $96.81 \%$, respectively. In general, slight differences in the profiles of volatile components were detected among the fruit samples from two different places. Fig. 3 shows the percentage concentration of different chemical groups in the SFE of $S$. chinensis fruits from Inje and Mungyeong. The SFE were mainly 
represented by sesquiterpene hydrocarbons followed by oxygenated sesquiterpenes, oxygenated monoterpenes and monoterpene hydrocarbons. When comparing the SFE obtained from Inje and Mungyeong fruits, sesquiterpene hydrocarbons were found to be higher level in Mungyeong samples (72.94\%) than Inje samples $(65.71 \%)$. On the other hand, Inje samples contained higher concentration of oxygenated sesquiterpenes $(16.88 \%)$ than Mungyeong samples.

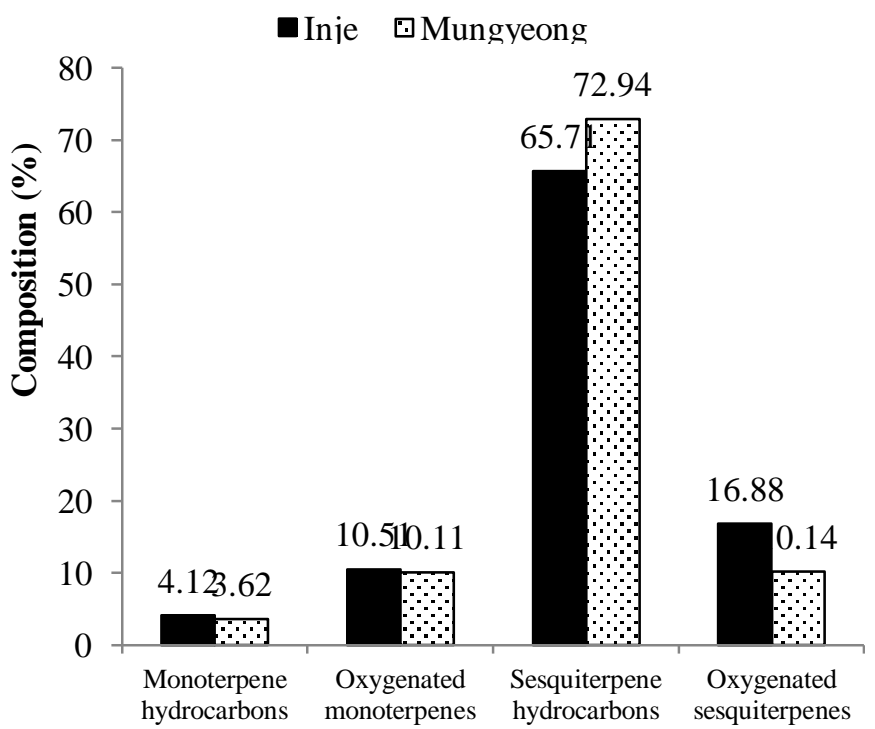

Fig. 3: Percentage composition of different chemical groups in the supercritical carbon dioxide extract of Schisandra chinensis fruits from two different places (Inje and Mungyeong).

Ylangene(17.66 and 25.66\%), $\alpha$-himachalene (20.70 and $18.03 \%)$, longipinene (10.09 and 8.69\%), italicene (5.32 and $4.86 \%$ ), bornyl acetate (3.54 and $4.31 \%$ ), aromadendrene epoxide (3.72 and 2.74\%)were recorded as the major components of the SFE (Inje and Mungyeong, respectively). In addition, considerable amount of cedr-8-en-15-ol (3.88\%) and acoradiene $(2.57 \%)$ were detected in the samples of Inje and Mungyeong, respectively. The major differences between the SFE of Inje and Mungyeong samples can be referred to ylangene, $\alpha$-himachalene and longipinene. The SFE of Mungyoeng sample contained higher concentration of ylangene $(25.66 \%)$ than Inje sample $(17.66 \%)$. Whereas Inje sample registered higher level of $\alpha$-himachalene $(20.70 \%)$ and longipinene $(10.09 \%)$ than Mungyoeng sample (18.03 and $8.69 \%$, respectively).

According to the previous reports, sesquiterpene hydrocarbons and oxygenated sesquiterpenes are the main volatile components from the fruits of $S$. chinensis and responsible for its specific fragrance. The results of the present study also clearly showed that the fruits mainly composed of sesquiterpenes group of components with ylangene, $\alpha$-himachalene, longipinene as the major components. In the previous report, 40 components were identified in the essential oil of $S$. chinensis fruits and the main components were ylangene $(37.72 \%), \beta$-himachalene $(10.46 \%)$ and $\alpha$-bergamotene $(8.57 \%$ ) (Chen et al., 2012). In another study,
Teng and Lee (2014) compared the simultaneous distillation extraction with Soxhlet and microwave assisted extraction methods. The results revealed that the major ingredients in the oil extracted by simultaneous distillation extraction were ylangene (15.01\%), $\alpha$-phellandrene $(8.23 \%), \beta$-himachalene $(6.95 \%)$, and cuparene $(6.74 \%)$. However, the oils obtained by other extraction methods mainly contained aromatics such as schisandrins and gomisin A.

Deng et al. (2003) compared the volatile composition of S. chinensis obtained from steam distillation and headspace SPME and identified 33 and 35 volatile compounds, respectively. Further, Li et al. (2003)investigated the essential oil composition of $S$. chinensis obtained from steam distillation and characterized 48 different volatile components from the oils.Wang et al. (2008) investigated the comparison of volatile composition from the fruits of $S$. chinensis obtained by SFE, steam distillation, Soxhlet extraction and ultrasound-assisted extraction and identified 37, 45, 27 and 37 compounds in the samples, respectively. Further, the authors stated that the SFE method shared 32 compounds in common with the other three methods. Among them, schisandrin (16.4\%), methostenol (16.2\%), and $\beta$-tocopherol (11.0\%), $\alpha$ ylangene (7.94\%) 2-methyl-2-bornene (7.64\%), 1-butyl-1,3,5,7cyclooctatetraene $(6.50 \%)$ and $\alpha$-farnesene $(5.58 \%)$ were the major components in the SFE.In the current study, totally 42 components (40 components from each place) were identified in the SFE of fruits. Ylangene, $\alpha$-himachalene, longipinene, italicene, bornyl acetate and aromadendrene epoxide were the most abundant components in the SFE.

The composition of SFE of S. chinensis fruits is totally different from previous report and analysis methods might be responsible for these variations (Wang et al., 2008). Moreover, this is the first report on the volatile composition of SFE of $S$. chinensis using SPME-GC/MS. The findings of the previous and the present studies clearly suggested that the volatile composition of $S$. chinensis fruits is mainly influenced by the extraction techniques, place of sample collection and environmental conditions (biotic and abiotic factors).

\section{CONCLUSION}

In the present investigation, the fruits of S. chinensis collected from both the places, Inje and Mungyoeng possess almost similar and appreciable levels of proximate composition, mineral contents, bioactive lignans and various volatile components. The considerable amount of nutrients and bioactive components in the $S$. chinensis fruits suggest that the fruits may have the potential for enriching ingredient for locally processed foods and can contribute to certain nutritional requirements in the human diet.

\section{ACKNOWLEDGEMENTS}

Financial support and sponsorship: This research was supported by the Ministry of Trade, Industry \& Energy (MOTIE), Korea Institute for Advancement of Technology (KIAT) through the 
Encouragement Program for The Industries of Economic Cooperation Region (No. R0004940).

Conflict of Interests: There are no conflicts of interest.

\section{REFERENCES}

Adams RP. 2007. Identification of essential oil components by gas Chromatography/ mass spectrometry. Carol Stream, IL, USA: Allured Publishing Co.

Ahmed Z, Abdeslam-Hassan M,Ouassila L, Danielle B.Extraction and modeling of Algerian rosemary essential oil using supercritical $\mathrm{CO}_{2}$ : Effect of pressure and temperature. Energy Procedia,2012; 18:1038-1046.

Ansari K,Goodarznia I. Optimization of supercritical carbon dioxide extraction of essential oil from spearmint (Mentha spicata L.) leaves by using Taguchi methodology. J Supercrit Fluid,2012; 67:123-130.

Association of Official Analytical Chemists (AOAC). 2000. Official Methods of Analysis of AOAC International, 17th ed. Gaithersburg, MD, USA: AOAC International.

Capuzzo A, Maffei ME, Occhipinti A. Supercritical fluid extraction of plant flavors and fragrances. Molecules,2013; 18:7194-7238.

Chen X, Zhang Y, Zu Y, Yang L. Chemical composition and antioxidant activity of the essential oil of Schisandra chinensis fruits. Nat Prod Res, 2012; 26:842-849.

Cheng N, Ren NY, Gao H, Lei X, Zheng J, Cao W. Antioxidant and hepatoprotective effects of Schisandra chinensis pollen extract on $\mathrm{CCl}_{4}$-induced acute liver damage in mice. Food ChemToxicol,2013; 55:234-40.

Choi YW, Takamatsu S, Khan SI,Srinivas PV, Ferreira D, Zhao $\mathrm{J}$, et al.Schisandrene, a dibenzocyclooctadienelignan from Schisandra chinensis : structure-antioxidant activity relationships of dibenzocyclooctadienelignans. J Nat Prod,2006; 69:356-359.

Delgado FJ, González-Crespo J, Cava R, García-Parra J, Ramirez R. Characterisation by SPME-GC-MS of the volatile profile of a Spanish soft cheese PDO.TortadelCasar during ripening. Food Chem, 2010; 118:182-189.

Deng C, Song G, Hu Y, Zhang X. Analysis of the volatile constituents of Schisandra chinensis (Turz.) Bail by gas chromatographymass spectrometry, using headspace solid-phase microextraction.Chromatographia, 2003; 58:289-294.

Dhouioui M, Boulila A, Chaabane H, Zina MS, Casabianca H. Seasonal changes in essential oil composition of Aristolochia longa L. ssp. paucinervisBatt. (Aristolochiaceae) roots and its antimicrobial activity.Ind Crop Prod, 2016;83:301-306.

Fornari T, Vicente G, Vázquez E, García-Risco MR, Reglero G. Isolation of essential oil from different plants and herbs by supercritical fluid extraction. J Chromatogr A, 2012; 1250:34- 48.

Gao XX, Li JH, Jiang GQ, Meng XJ. Ultrasonic wave extraction of polysaccharide from fruit of Schisandra chinensis and its antioxygenic property to oil. J Northeast Forestry Uni,2009; 37:34-36.

Giridharan VV, Thandavarayan RA, Bhilwade HN, Ko KM, Watanabe K, Konishi T.Schisandrin B attenuate scisplatin-induced oxidatives tress, genotoxicity and neurotoxicity through modulating NFkB pathway in mice. Free Radic Res,2012;46:50-60.

Giridharan VV, Thandavarayan RA, Sato S, Ko KM, Konishi T. Prevention of scopolamine-induced memory deficits by schisandrinB, an antioxidant lignan from Schisandra chinensis in mice. Free Radic Res2011;45:950-958.

Herrero M, Mendiola JA, Cifuentes A, Ibanez E. Supercritical fluid extraction: recent advances and applications. J Chromatogr A,2010; 1217:2495-2511.

Hu J, Mao C, Gong X, Lu T, Chen H, Huang Z, et al. Simultaneous determination of eleven characteristic lignans in Schisandra chinensis by high-performance liquid chromatography. Pharmacogn Mag,2013;9:155-161.

Hu D, Li C, Han N, Miao L, Wang D, Liu Z, et al. Deoxyschizandrin isolated from the fruits of Schisandra chinensis ameliorates $A \beta_{1-42}$-induced memory impairment in mice. Planta Med,2012; 78:1332-1336.

Huang F,Xiong YT, Xu LH, Ma SP, Dou CG. Sedative and hypnotic activities of the ethanol fraction from Fructus Schisandraein mice and rats.J Ethnopharmacol,2007; 110:471-475.

Huang SX, Han QB, Lei C, Pu JX, Xiao WL, Yu JL, et al.Isolation and characterization of miscellaneous terpenoids of Schisandra chinensis . Tetrahedron, 2008; 64:4260-4267.

Hwang K, Kim O, Lee C, Lee Y, Kim H, Yoo I, et al.Mineral contents and transfer rate in Schizandra chinensis fruits and their infusions by extraction method. J FoodHyg Safety,2015; 30:87-91.

Ip SP, Poon MKT, Che CT, Ng KH, Kong YC, Ko RKM. Schisandrin B protects against carbon tetrachloride toxicity by enhancing the mitochondrial glutathione redox status in mouse liver. Free RadicBiolMed,1996; 21:709-712.

Iqbal S, Younas U, Sirajuddin Chan KW, Sarfraz RA, Uddin K. Proximate composition and antioxidant potential of leaves from three varieties of Mulberry Schizandra chinensis: a comparative study. Int JMolSci,2012; 13:6651-6664.

Jeong HJ, Han NR, Kim KY, Choi IS, Kim HM. Gomisin A decreases the LPS-induced expression of iNOS and COX-2 and activation of RIP2/NF-kB in mouse peritoneal macrophages. Immunopharmacol Immunotoxicol, 2014; 36:195-201.

Jiang SL, Zhang YY, Chen DF. Effects of heteroclitin D, schisanhenol and (+)-anwulignan on platelet aggregation. FudanUniv J Med Sci,2005; 32:467-471.

Kang K, Lee KM, Yoo JH, Lee HJ, Kim CY, Nho CW. Dibenzocyclooctadienelignans, Gomisins $\mathrm{J}$ and $\mathrm{N}$ inhibit theWnt/B-catenin signaling pathway in HCT116 cells. BiochemBiophys Res Commun,2012; 428:285-291.

Kim JH, Choi YW, Park C, Jin CY, Lee YJ, Park DJ, et al.Apoptosis induction of human leukemia U937 cells by gomisin N, a dibenzocyclooctadienelignan, isolated from Schizandra chinensis Baill.Food ChemToxicol,2010; 48:807-813.

Kim JS, Choi SY. Physicochemical properties and antioxidative activities of omija (Schizandra chinensis Bailon). Korean J Food Nutr,2008; 21:35-42.

Lee HJ, Kim CY. Simultaneous determination of nine lignans using pressurized liquid extraction and HPLC-DAD in the fruits of Schisandra chinensis . Food Chem,2010; 120:1224-1228.

$\mathrm{Li} \mathrm{L}, \mathrm{Lu}$ Q, Shen Y, Hu X. Schisandrin B enhances doxorubicin-induced apoptosis of cancer cells but not normal cells. BiochemPharmacol,2006; 71:584-595.

Li XN, Cui H, Song YQ, Liang YZ, Chau FT. Analysis of volatile fractions of Schisandra chinensis (Turcz.) Baill.using GC-MS and chemometric resolution. Phytochem Anal,2003; 14:23-33.

$\mathrm{Lu} \mathrm{Y,} \mathrm{Chen} \mathrm{DF.} \mathrm{Analysis} \mathrm{of} \mathrm{Schisandra} \mathrm{chinensis} \mathrm{and}$ Schisandra sphenanthera. J Chromatogr A, 2009; 1216:1980-1990.

$\mathrm{Lu}$ Y, Wang WJ, Song YZ, Liang ZQ. The protective mechanism of schisandrin A in D-galactosamine-induced acute liver injury through activation of autophagy.Pharm Biol2014; 52:13021307.

Min HY, Park EJ, Hong JY, Kang YJ, Kim SJ, Chung HJ, et al.Antiproliferative effects of dibenzocyclooctadienelignans isolated from Schisandra chinensis in human cancer cells. Bioorg Med ChemLett, 2008; 18:523-526.

Nour V, Trandafir I, Cosmulescu S. Antioxidant capacity, phenolic compounds and minerals content of blackcurrant (Ribes nigrum L.) leaves as influenced by harvesting date and extraction method. Ind Crop Prod,2014; 53:133-139.

Oh SY, Kim YH, Bae DS, Um BH, Pan CH, Kim CY, et al. Anti-inflammatory effects of gomisin N, gomisin $\mathrm{J}$, and schisandrin $\mathrm{C}$ isolated from the fruit of Schisandra chinensis. Biosci Biotechnol Biochem, 2010; 74:285-291.

Park JY, Yun JW, Choi YW, Bae JU, Seo KW, Lee SJ, et al. Antihypertensive effect of gomisin A from Schisandra chinensis on angiotensin II-induced hypertension via preservation of nitric oxide bioavailability. Hypertens Res, 2012; 35:928-934. 
Park SY, Park DJ, Kim YH, Kim YJ, Kim SG, Shon KJ, et al.Upregulation of heme oxygenase-1 via PI3K/Akt and Nrf-2 signaling pathways mediates the anti-inflammatory activity of Schisandrin in Porphyromonas gingivalis LPS-stimulated macrophages. Immunol Lett, 2011; 139:93-101.

Stacchiotti A, Li Volti G, Lavazza A, Rezzani R,Rodella LF. Schisandrin B stimulates a cytoprotective response in rat liver exposed to mercuric chloride. Food ChemToxicol, 2009; 47:2834-2840.

Sun Y, Wen X, Huang H. Population genetic differentiation of Schisandra chinensis and Schisandra sphenanthera as revealed by ISSR analysis. Biochem Syst Ecol, 2010; 38:257-263.

Takimoto Y, Qian H-Y, Yoshigai E, Okumura T, Ikeya Y, Nishizawa M. Gomisin $\mathrm{N}$ in the herbal drug gomishi (Schisandra chinensis ) suppresses inducible nitric oxide synthase gene via $\mathrm{C} / \mathrm{EBPb}$ and NF-jB in rat hepatocytes. Nitric Oxide, 2013; 28:47-56.

Teng H, Lee, WY. Antibacterial and antioxidant activities and chemical compositions of volatile oils extracted from Schisandra chinensis Baill. seeds using simultaneous distillation extraction method, and comparison with Soxhlet and microwave assisted extraction. Biosci Biotechnol Biochem, 2014; 78:79-85.

Wang L, Chen Y, Song Y, Chen Y, Liu X. GC-MS of volatile components of Schisandra chinensis obtained by supercritical fluid and conventional extraction. J Sep Sci,2008; 31:3238-3245

Xie Y, Hao H, Kang A, Liang Y, Xie T, Sun S, et al. Integral pharmacokinetics of multiple lignan components in normal, $\mathrm{CCl}_{4}$-induced hepatic injury and hepatoprotective agents pretreated rats and correlations with hepatic injury biomarkers. J Ethnopharmacol,2010; 131:290-299.

Zhang $\mathrm{H}$, Zhang $\mathrm{G}$, Zhu Z, Zhao L, Fei Y, Jing J, et al.Determination of six lignans in Schisandra chinensis (Turcz.) Baill. Fruits andrelated Chinese multiherb remedies by HPLC. Food Chem, $2009 ; 115: 735-739$.

Zhang Q, Zhu W, Guan H, Liu H, Yang W, Wang H, et al.Development of a matrix solid-phase dispersion extraction combinedwith high-performance liquid chromatography for determination offivelignans from the Schisandra chinensis. J Chromatogr B,2016; 1011:151-157.

\section{How to cite this article:}

Sowndhararajan K, Kim TH, Kim H, Kim S. Evaluation of proximate composition,bioactive lignansand volatile composition of Schisandra chinensis fruitsfrom Inje and Mungyeong, Republic of Korea. J App Pharm Sci, 2016; 6 (11): 001-008. 